\title{
Amniotic membrane transplantation in the management of conjunctival malignant melanoma and primary acquired melanosis with atypia
}

\author{
Dion Paridaens, Houdijn Beekhuis, Willem van den Bosch, Lies Remeyer, Gerrit Melles
}

\begin{abstract}
Aim-To evaluate the efficacy of amniotic membrane transplantation (AMT) for the management of conjunctival malignant melanoma and primary acquired melanosis (PAM) with atypia.

Methods-Four consecutive patients with histologically proved invasive, primary conjunctival malignant melanoma were treated with wide surgical excision and AMT. Amniotic membrane grafts were harvested and processed under sterile conditions according to a standard protocol. The grafts were sutured to the margins of the surface defect. In one case, AMT was combined with a corneoscleral graft.

Results-A satisfactory result and rapid postoperative recovery with few, transient side effects was noted in three patients with limbal/epibulbar melanomas. In another patient with an extensive lesion, involving the epibulbar, forniceal, and palpebral conjunctiva, AMT following wide excision was complicated by symblepharon formation and restricted ocular motility. Monitoring of local recurrence was facilitated by the transparency of the thin graft in all cases. The postoperative follow up time varied between several months and 3 years. In one case, local recurrence of PAM was observed and treated using topical mitomycin.

Conclusions-AMT is a useful technique lows for monitoring of tumour recurrence, which is-together with superior cosmesis-an advantage over thicker (for example, buccal) mucous membrane grafts.

(Br F Ophthalmol 2001;85:658-661)
\end{abstract}

Hospital, Oculoplastic

Service

D Paridaens

W van den Bosch

Corneal Service

$\mathrm{H}$ Beekhuis

L Remeyer

G Melles

Correspondence to: D Paridaens, Rotterdam Eye Hospital, Schiedamsevest 180, PO Box 70030, 3000 LM Rotterdam, Netherlands paridaens@ned.net

Accepted for publication 13 February 2001
The surgical management of conjunctival malignant melanoma constitutes a clinical challenge, especially when the tumour is large or arises multifocally, as in primary acquired melanosis (PAM) with atypia. ${ }^{1}$ For both conditions, wide conjunctivectomy may be indicated. The most radical method of eradicating diseased conjunctiva is orbital exenteration. This mutilating operation has been largely abandoned as a primary procedure, as it does not lead to increased survival in patients with conjunctival malignant melanoma. ${ }^{2}$ Instead, most clinicians now reserve orbital exenteration to locally control advanced stages of this neoplasm. More conservative and patient friendly surgical techniques include the "bare sclera" or "primary closure" methods for smaller lesions and the use of autografts or allografts to replace larger areas of excised conjunctiva. Non-surgical methods to treat conjunctival malignant melanoma and PAM include cryotherapy, radiotherapy, and topical chemotherapy, which are now mostly used as adjunctive tools in the management of these neoplasms. ${ }^{13}$

The use of fetal membrane allografts, including both amnion and chorion, for ophthalmic purposes was first reported by de Rotth in $1940 .{ }^{4}$ Recently, amniotic membrane transplantation (AMT) was introduced by Tseng and colleagues for the management of patients with corneal defects, pterygia, neoplasia, and symblepharon..$^{5-7}$ Amniotic membrane promotes epithelialisation and inhibits fibrosis. ${ }^{8}$ The techniques to harvest and preserve human amniotic membranes have been well established..$^{5-9}$ The use of this graft is considered safe, as long as the preparation is done according to a standard protocol..$^{5-8}$

Recently, a case of successful AMT was reported in a patient with an amelanotic corneal and limbal malignant melanoma originating from PAM. ${ }^{7}$ This prompted us to use AMT for surface reconstruction following wide excision of conjunctival malignant melanomas. We report on our experience with AMT in the management of four such cases.
Patients and methods

Between 1998 and 2000, four patients with primary conjunctival malignant melanoma 
Table 1 Clinical findings and outcome of four patients with conjunctival melanoma following wide excision and amniotic membrane transplantation

\begin{tabular}{|c|c|c|c|c|c|c|c|c|c|c|c|}
\hline \multirow{2}{*}{$\begin{array}{l}\text { Case No, age } \\
\text { at time of } \\
\text { diagnosis, sex }\end{array}$} & \multirow[b]{2}{*}{ Precursor } & \multirow{2}{*}{$\begin{array}{l}\text { Location of } \\
\text { conjunctival } \\
\text { melanoma } \\
\text { (and PAM) }\end{array}$} & \multirow{2}{*}{$\begin{array}{l}\text { Breslow } \\
\text { thickness } \\
\text { (mm) }\end{array}$} & \multirow{2}{*}{$\begin{array}{l}\text { Primary } \\
\text { treatment }\end{array}$} & \multicolumn{2}{|c|}{$\begin{array}{l}\text { Completely } \\
\text { resected }\end{array}$} & \multirow{2}{*}{$\begin{array}{l}\text { Secondary } \\
\text { treatment }\end{array}$} & \multirow{2}{*}{$\begin{array}{l}\text { Follow up } \\
\text { (months) }\end{array}$} & \multirow{2}{*}{$\begin{array}{l}\text { Cosmetic } \\
\text { outcome }\end{array}$} & \multirow{2}{*}{$\begin{array}{l}\text { Signs of } \\
\text { recurrence at } \\
\text { end follow up }\end{array}$} & \multirow{2}{*}{$\begin{array}{l}\text { Fibrotic } \\
\text { reaction/symblepharon }\end{array}$} \\
\hline & & & & & $M M^{\star}$ & $P A M \dagger$ & & & & & \\
\hline $1 ; 49 ; M$ & $\begin{array}{l}\text { PAM + } \\
\text { naevus }\end{array}$ & $\begin{array}{l}\text { corneolimbal; } \\
\text { epibulbar }\end{array}$ & 2.6 & $\begin{array}{l}\text { wide excision }+ \\
\text { corneoscleral } \\
\text { graft + AMT } \ddagger\end{array}$ & yes & no & $\begin{array}{l}\text { Cryotherapy; } \\
\text { topical } \\
\text { mitomycin } 0.02 \%\end{array}$ & 16 & excellent & no & - \\
\hline $2 ; 70 ; \mathrm{F}$ & PAM & $\begin{array}{l}\text { limbal; epibulbar; } \\
\text { plica; caruncle; } \\
\text { forniceal; palpebral }\end{array}$ & 2.1 & $\begin{array}{l}\text { wide excision } \\
+\mathrm{AMT}\end{array}$ & yes & no & $\begin{array}{l}\text { Topical } \\
\text { mitomycin } 0.02 \%\end{array}$ & 16 & moderate & yes (PAM) & ++ \\
\hline $3 ; 54 ; M$ & de novo & $\begin{array}{l}\text { corneolimbal; } \\
\text { epibulbar }\end{array}$ & 2.7 & $\begin{array}{l}\text { wide excision } \\
+ \text { cryotherapy } \\
+ \text { corneoscleral } \\
\text { graft + AMT }\end{array}$ & yes & - & - & 28 & good & no & + \\
\hline $4 ; 64 ; M$ & naevus & limbal; epibulbar & 1.6 & $\begin{array}{l}\text { wide excision } \\
+\mathrm{AMT}\end{array}$ & yes & - & - & 5 & excellent & no & - \\
\hline
\end{tabular}

${ }^{\star} \mathrm{MM}=$ malignant melanoma.

†PAM = primary acquired melanosis.

ҒAMT = amniotic membrane transplantation.

were treated with excisional surgery and AMT in our clinic.

PREPARATION OF AMNIOTIC MEMBRANE

The preparation of amniotic membrane was performed according to a protocol, recently reported elsewhere, ${ }^{8}$ which has been derived from earlier work by Tseng et al..$^{5-7}$ In brief, amniotic membrane is obtained under sterile conditions after elective caesarean delivery from a HIV seronegative donor. The amniotic membrane is separated from other placental tissues by blunt dissection, after washing with $0.01 \mathrm{M}$ phosphate buffered saline (PBS) containing $100 \mathrm{mg}$ dibekacin sulphate. The membrane is then cut in pieces, measuring $5 \times$ $5 \mathrm{~cm}$ and rinsed three times in $0.01 \mathrm{M}$ PBS. Then it is mounted on nitrocellulose paper with the epithelial side down and stored frozen at $-80^{\circ} \mathrm{C}$ until use. Preoperatively, the membrane is warmed to room temperature, and then rinsed three times in 0.01 M PBS, and in $0.01 \mathrm{M}$ PBS containing $100 \mathrm{mg}$ of dibekacin sulphate.

SURGICAL TECHNIQUE OF AMNIOTIC MEMBRANE GRAFTING

After trimming it to the appropriate size, the amniotic membrane graft is sutured with the epithelial side up to the corneal or conjunctival margins of the defect using 10-0 nylon and 9-0 Vicryl respectively. Postoperatively, the patient is fitted with a bandage lens if required, and is treated with topical antibiotics and steroids for several weeks.

\section{Results}

The clinical data of the four patients have been summarised in Table 1.

In case 1 , an extensive, partly elevated malignant melanoma in the context of PAM (and a naevus) of the temporal quadrants of the epibulbar conjunctiva, extending onto the limbus and temporal cornea (Fig 1(A1)) was treated by wide excision with a free margin of 3 $\mathrm{mm}$, followed by lamellar keratectomy (1.5 $\mathrm{mm}$ wide) and sclerectomy (4 $\mathrm{mm}$ wide). A corneoscleral graft was sutured in, followed by amniotic membrane grafting over the entire defect (Fig 1(A3)).
As the PAM component microscopically reached to the inferior corneal margin of resection, this area was treated with three freezethaw cycles of cryotherapy followed by topical mitomycin $0.02 \%$ three times daily for 4 weeks. After mild discomfort and transient redness of his left eye for several weeks, the patient recovered well and has had an excellent cosmetic appearance (Fig 1(A2)).

In case 2 , a partly pigmented elevated malignant melanoma involved the medial area of epibulbar conjunctiva, the plica, and caruncle (Fig 1(B1)). A surrounding area of lightly pigmented melanosis extended to the medial part of the superior fornix and palpebral conjunctiva and downwards to the lower lid margin. The clinically affected conjunctiva, plica, and caruncle were excised "en bloc" with a free margin of $3 \mathrm{~mm}$. The resulting defect was covered with two amniotic membrane grafts, which merged at the superior fornix (Fig 1(B3)). The postoperative course was good, with mild discomfort for the patient. In the first weeks, during treatment with topical antibiotics and steroids, there was no sign of symblepharon formation. There was residual melanosis at the lower lid margin and inferior corneal limbus and conjunctiva. Four weeks postoperatively, after tapering of the topical steroids, a fibrotic reaction underneath the amniotic membrane graft was noted, both near the medial canthal area and in the superior fornix, leading to symblepharon and slightly disturbed ocular motility (Fig 1(B2)). Recurrent PAM at the $4-5$ o'clock area was treated with topical mitomycin $0.02 \%$ three times daily for 3 weeks.

In case 3 , a limbal, amelanotic malignant melanoma of $6 \mathrm{~mm}$ diameter and $2 \mathrm{~mm}$ elevation (Fig 1(C1)) was biopsied and later completely excised, followed by cryotherapy of the wound bed (Fig 1(C3)). The defect was covered with an amniotic membrane graft. During the follow up period of more than 2 years, a pterygium-like reaction was observed at the transplanted area, with fibrosis and hyperaemia (Fig 1(C2)), causing slight astigmatism, but no signs of tumour recurrence.

In case 4 , a nodular malignant melanoma at the temporal limbus with a diameter of $6 \mathrm{~mm}$ 


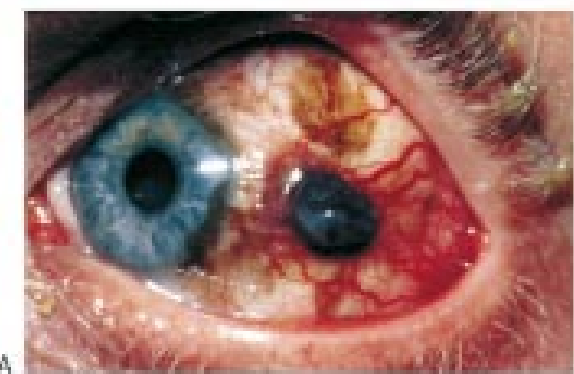

1

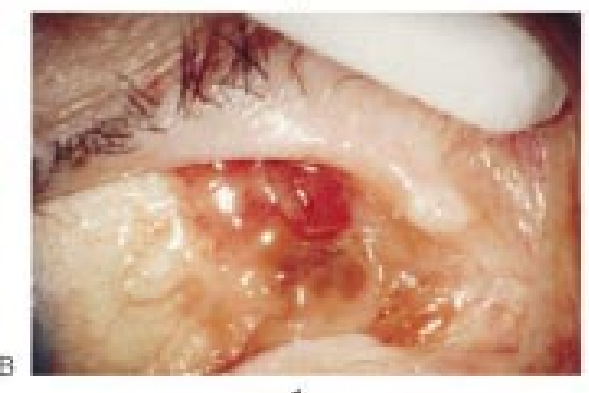

1

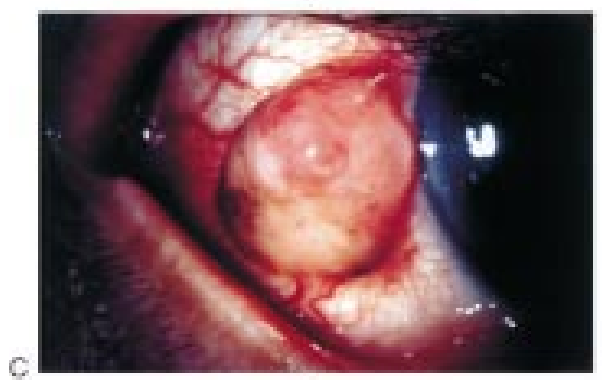

1

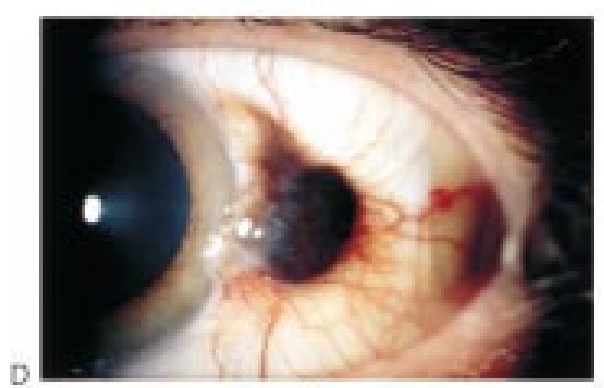

1

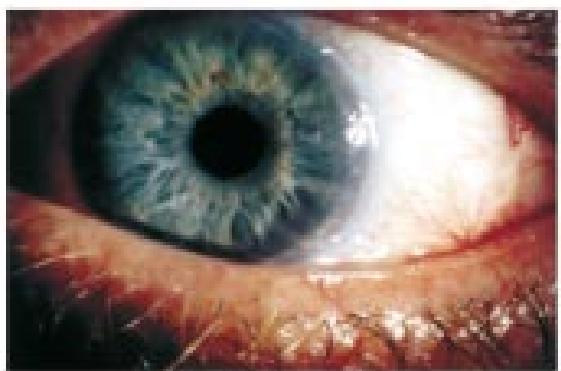

2

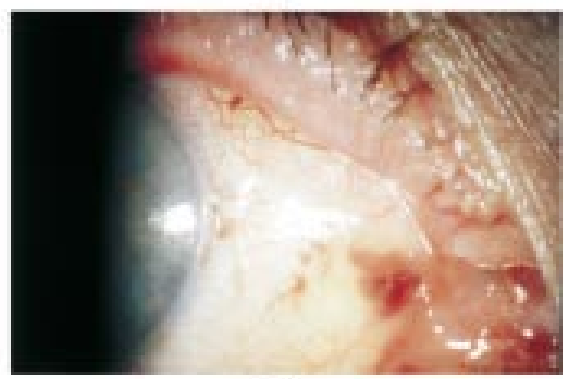

2
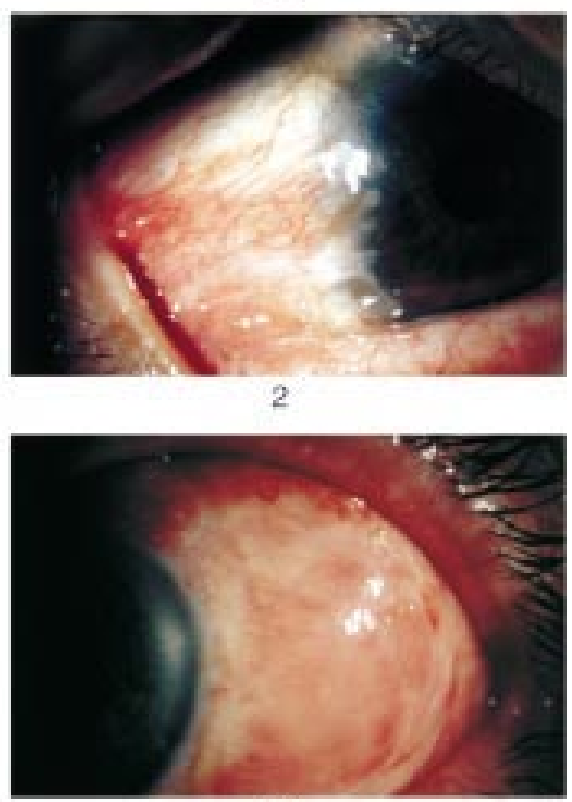

2

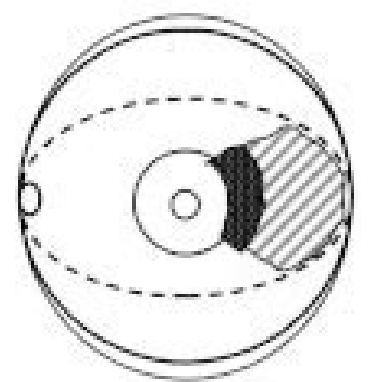

3

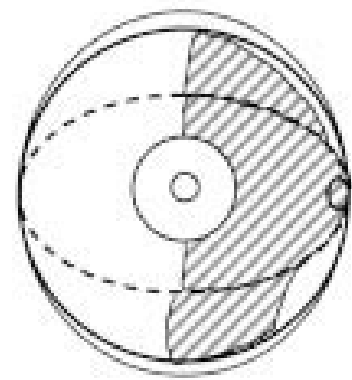

3
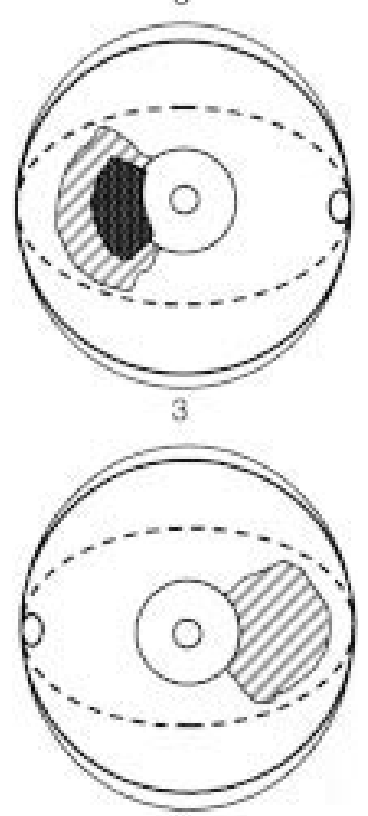

3

Conjunctival

resection

Comececlera resection

Figure 1 (A1) Preoperative view of a nodular, deeply pigmented conjunctival malignant melanoma arising in the context of primary acquired melanosis and a naevus in the temporal (epibulbar) quadrants of the left eye in a 49 year old man (case 1). (A2) Excellent cosmetic and functional result at 8 weeks after conjunctival and corneoscleral excisional surgery, corneoscleral grafting combined with amniotic membrane grafting (AMT), followed by cryotherapy and a topical mitomycin course (case 1). (A3) Schematic drawing depicting the areas of conjunctival and corneoscleral resection in case 1. (B1)

Preoperative view of an irregular, partly pigmented elevated malignant melanoma involving the medial area of epibulbar conjunctiva, the plica, and the caruncle of the right eye in a 70 year old woman. The tumour originates from flat, lightly pigmented melanosis, extending into the medial part of the superior and inferior fornix and palpebral conjunctiva, and the lower lid margin (case 2). (B2) At 3 weeks after excisional surgery and AMT, while the patient was still using topical steroids, there was no sign of symblepharon formation. In the following weeks, when the steroids were tapered down, a fibrotic reaction underneath the amniotic membrane was noted (case 2). (B3) Schematic drawing depicting the areas of excised conjunctiva in case 2. (C1)

Preoperative view of a nodular, amelanotic malignant melanoma at the limbus of the right eye in a 54 year old Asian man (case 3). (C2) No sign of local recurrence at 2 years following excisional surgery, cryotherapy, and AMT. Note the pterygium-like reaction of the transplanted area, with mild fibrosis and hyperaemia (case 3). (C3) Schematic drawing depicting the areas of corneoscleral and conjunctival resection in case 3. (D1) Preoperative view of a nodular, darkly pigmented, limbal malignant melanoma of the left eye in a 64 year old man (case 4). (D2) Satisfactory cosmetic and functional result at 4 weeks following tumour excision and AMT. The oedema and hyperaemia of the graft area is subsiding (case 4). (D3) Schematic drawing depicting the areas of conjunctival resection in case 4. 
(Fig 1(D1)), which had originated from a preexisting naevus, was excised with clinically free margins of $3 \mathrm{~mm}$. The defect was closed with an amniotic membrane graft (Fig 1(D3)). In the postoperative phase, the graft exhibited epithelial overgrowth, and transient oedema and hyperaemia (Fig 1(D2)).

\section{Discussion}

These four cases demonstrate the successful use of AMT for the reconstruction of ocular surface defects following surgical excision of conjunctival malignant melanoma and PAM.

The advantages of this new technique for this indication include: (1) the cosmetic appearance following surgery, (2) the absence of donor site morbidity complicating the harvest of mucosal autografts, and (3) the ability to clinically monitor local recurrence of tumour underneath the transparent amniotic membrane graft. Furthermore, for more advanced cases, in which there is extensive, superficial conjunctival involvement, this technique may preclude or at least postpone a mutilating orbital exenteration. ${ }^{2}$

AMT caused short term mild ocular discomfort and redness due to oedema and hyperaemia, which responded well to topical steroids and antibiotics. In the longer term, symblepharon formation and restricted ocular motility were noted in one case (no 2), in which the extensive tumour involved both the epibulbar, the forniceal, and the palpebral conjunctiva and the caruncle. In this case, two amniotic membrane grafts were sutured into the defects of, respectively, the epibulbar and palpebral conjunctiva. We speculate that a continuous layer of amniotic membrane, stretching from the epibulbar area via the fornix to the anterior margin of the upper lid might have caused less symblepharon formation. Furthermore, the patient in case 3 developed a mild pterygium-like fibrotic reaction, while in case 4 the follow up time has been too short to evaluate this complication.

In the four cases, alternative methods to cover the conjunctival surface defects, including conjunctival or other mucosal autografts, could have been used. The defects were considered to be too large for primary closure or leaving the sclera uncovered (bare sclera technique). The use of conjunctival autografts was also regarded as unappealing, since the harvest of these grafts may inflict serious donor site morbidity, including symblepharon or restricted ocular or eyelid motility. Furthermore, patients may refuse to have an operation on their unaffected eye for donor purposes. In a recent comparative study between the use of conjunctival autografts, amniotic membrane grafts, and primary closure in the management of pterygia, the investigators felt that, despite the better results following the use of conjunctival autografts, AMT may be considered as an alternative first choice treatment. ${ }^{6}$ The use of thicker mucosal grafts - for example, buccal or inner lip, has cosmetic disadvantages compared with AMT, especially when visible areas of (epibulbar) conjunctiva are involved. Also, these thicker grafts may mask tumour growth underneath for a long time. ${ }^{2}$

We conclude that AMT is a promising technique in the treatment of the large ocular surface defects resulting from the radical excision of malignant melanoma and PAM. It facilitates extensive conjunctivectomy, which is required for larger or diffuse "multicentric" melanoma or melanosis, especially when the tumour is amelanotic. ${ }^{10}$ In our study with a follow up of several months up to 3 years, AMT was complicated by mild symblepharon and fibrosis in two of four cases. Our cases as well as the case reported by Tseng et al suggest that the best results of AMT are likely to occur in patients with limbal or epibulbar melanomas. Further study into the prevention of symblepharon complicating AMT is needed to increase the functional and cosmetic outcome of treated patients.

The authors gratefully acknowledge the support of the Eye Hospital Research Foundation (SWOO-Flieringa) in the preparation of this paper.

Ineke Beekhuis is gratefully acknowledged for her assistance in producing Figure 1.

1 Seregard S. Conjunctival melanoma. Surv Ophthalmol 1998;42:321-50.

2 Paridaens ADA, McCartney ACE, Minassian DC, et al. Orbital exenteration in 95 cases of primary conjunctival malignant melanoma. Br f Ophthalmol 1994;78:520-8.

3 Demirci H, McCormick SA, Finger PT. Topical mitomycin chemotherapy for conjunctival malignant melanoma and primary acquired melanosis with atypia. Clinical experience with histopathologic observations. Arch Ophthalmol

4 De Rotth A. Plastic repair of conjunctival defects with fetal membrane. Arch Ophthalmol 1940;23:522-5.

5 Lee SH, Tseng SCG. Amniotic membrane transplantation for persistent epithelial defects with ulceration. Am $\mathcal{F} O p h$ thalmol 1997;123:303-12.

6 Prabhasawat P, Barton K, Burkett G, et al. Comparison of conjunctival autografts, amniotic membrane grafts, and primary closure for pterygium excision. Ophthalmology 1997;104:974-85.

7 Tseng SCG, Prabhasawat P, Lee SH. Amniotic membrane transplantation for conjunctival surface reconstruction. Am f Ophthalmol 1997;124:765-74.

8 Dua SH, Azuara-Blanco A. Amniotic membrane transplantation. Br F Ophthalmol 1999;83:748-52.

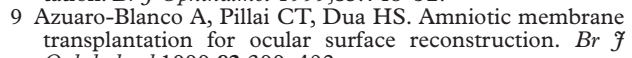
transplantation for ocular su

10 Paridaens ADA, McCartney ACE, Hungerford JL. Multifocal amelanotic conjunctival melanoma and acquired melanosis sine pigmento. Br f Ophthalmol 1992;76:163-5. 